\title{
PENGGUNAAN KOMPUTER DAN PENGOLAHAN DATA DENGAN MICROSOFT EXCEL PADA POSYANDU ASOKA II JATIRANGGON BEKASI
}

\author{
Nunu Kustian'), Nurul Badriyatul Muthoharoh' ${ }^{2)}$, Rizki Ridwan ${ }^{3)}$ \\ Program Studi Informatika, Fakultas Teknik dan Ilmu Komputer, Universitas Indraprasta PGRI
}

\begin{abstract}
Abstrak
Kegiatan Posyandu di dalam masyarakat merupakan kegiatan yang wajib dilakukan sebulan sekali oleh Kader Posyandu yang kompeten dalam membantu program pemerintah di bidang kesehatan dan dibantu dengan adanya buku panduan Posyandu sebagai acuan dalam pelaksanaannya, akan tetapi pada Posyandu Asoka II Jatiranggon Bekasi dikarenakan kegiatan Posyandu masih dilakukan secara manual menyulitkan kader dalam pengolahan data dalam melaporkan kegiatannya sehingga membutuhkan waktu yang lama. Untuk mengatasi permasalahan tersebut dilakukan sosialisasi sederhana untuk memanfaatkan komputer dan penggunaan Microsoft Excel sebagai database nya. Hasil dari sosialisasi ini meningkatkan pemahaman dan keterampilan kader Posyandu Asoka II Jatiranggon Bekasi dalam menggunakan komputer dan pemeliharaan data sehingga berkurangnya kesulitan dalam mengolah data.
\end{abstract}

Keywords: Komputer, Pengolahan Data, Microsoft Excel, Posyandu

\begin{abstract}
Posyandu activities in the community are activities that must be carried out once a month by Posyandu Cadres who are competent in assisting government programs in the health sector and assisted with the Posyandu guidebook as a reference in its implementation, but at Asoka II Jatiranggon Bekasi Posyandu due to recording of Posyandu activities manually making it difficult for cadres in processing data in reporting their activities so that it takes a long time. To overcome this problem, a simple socialization was carried out to use a computer and use Microsoft excel as its database. The results of this socialization increased the understanding and skills of the Asoka II Posyandu cadres Jatiranggon Bekasi in using computers and maintaining data so that there was less difficulty in processing data.
\end{abstract}

Keywords: : Computers, Data Processing, Microsoft Excel, Posyandu

Correspondence author: Nunu Kustian, kustiannunu@gmail.com, Jakarta, and Indonesia (i) (8)

This work is licensed under a $C C-B Y-N C$

\section{PENDAHULUAN}

Sistem informasi yang baik akan mendatangkan manfaat yang baik bagi organisasi atau instansi maka diperlukan suatu media atau alat pendukung yang dapat menyajikan informasi tersebut yang tak lain lagi adalah komputer. 
Penerapan sistem pengolahan data sangat dibutuhkan pada berbagai bidang, baik diinstansi pemerintah, pendidikan swasta, kesehatan, maupun usaha lain. Salah satu pelayanan pada bidang kesehatan yang terdapat di masyarakat adalah posyandu. Posyandu (Pos Pelayanan Terpadu) adalah suatu bentuk kegiatan swadaya masyarakat di bidang kesehatan yang dilaksanakan di suatu wilayah kerja Puskesmas, yang didalamnya terdapat kegiatan diantaranya berat badan, imunisasi, pemberian vitamin yang tersimpan dalam Kartu Menuju Sehat (KMS). (Prigianata, 2013). Secara umum Posyandu memiliki lima program utama yaitu Kesehatan Ibu dan Anak (KIA), Keluarga Berencana (KB), gizi, imunisasi, serta penanggulangan diare (Kemenkes R.I., 2012). Ini menjadikan kesehatan anak an kesehatan ibu menjadi prioritas yang perlu diperhatikan (Sholiha, Nabila., kusumadewi, 2015). Kesehatan merupakan faktor penting dalam pembangunan manusia yang berkualitas. Sehingga merupakan salah satu penentu Indeks Pembangunan Manusia (IPM), selain Pendidikan dan Pendapatan (DEPKES-RI, 2011).

Pengolahan data Posyandu secara manual mempunyai banyak kelemahan selain membutuhkan waktu yang lama, keakuratannya juga kurang dapat diterima, karena kemungkinan kesalahan sangat bersar. Penyimpanan data pada Posyandu ini masih berupa file-file terpisah sehingga memungkinkan data hilang dan mudah dimanipulasi. Kegiatan penimbangan, pencatatan, rekapitualsi, dan pelaporannya saat ini masih dilakukan secara manual. Menurut survei sederhana yang telah dilakukan ke Posyandu Asoka II Jatiranggon memerlukan waktu yang lama dan rentan terhadap kesalahan. Sementara kegiatan Posyandu tepatnya di Posyandu Asoka II Jatiranggon semakin aktif dan banyak pserta porsyandu terutama kegiatan KIA, KB dan penimbangan, sehingga petugas atau kader yang melayani semakin sulit dalam proses administrasi pencatatan, pengolahan, dan pelaporan setiap saat dan periode. Dengan dukungan teknologi informasi pengolahan data manual dapat digantikan dengan sistem pengolahan data dengan komputer.

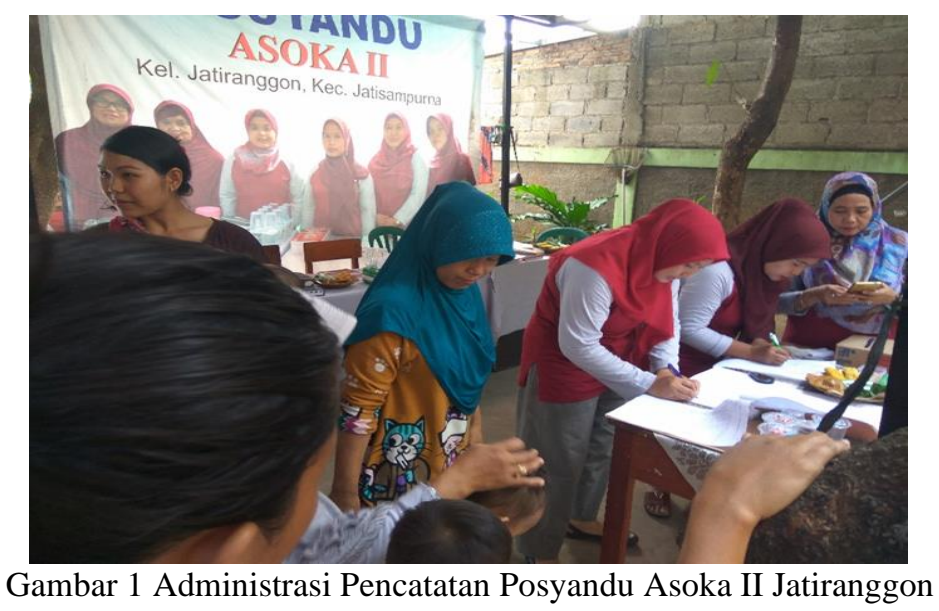

Berdasarkan identifikasi lapangan dan diskusi para kader di lapangan, maka tim abdimas tertarik untuk melakukan Pengabdian Kepada Masyarakat kepada Posyandu Asoka II Kel. Jatiranggon sebagai upaya memberikan solusi dengan memanfaatkan komputer sebagai awal pembelajaran untuk mengolah data Posyandu agar lebih mudah dan cepat sehingga pencatatan sederhana tidak dipakai lagi di sistem yang lama. Dalam hal ini penulis menggunakan microsoft Excel sebagai database nya yang bertujuan untuk mengurangi kesalahaan pendataan balita, pendaftaran baru, dan pencatatan agar lebih 
cepat atau up to date sesuai dengan kebutuhan kader. Sehingga kebenaran isi database sangat berpengaruh pada kualitas laporan atau informasi yang dihasilkan.

\section{METODE PELAKSANAAN}

Penggunaan komputer yang digunakan dalam mengolah data menjadi informasi merupakan hasil pengolahan dari sebuah model, formasi, organisasi, ataupun suatu perubahan bentuk dari data yang memiliki nilai tertentu, dan bisa digunakan untuk menambah pengetahuan bagi yang menerimanya.

Metode yang digunakan dalam pengabdian mayarakat ini adalah metode seminar ceramah. Menurut (Efendi, 2018) dalam Buku Sagala H. Syaiful 2006 "Metode Ceramah adalah sebuah bentuk interaksi melalui penerangan dan penuturan lisan dari guru kepada peserta didik. Dalam pelaksanaan ceramah untuk menjelaskan uraiannya, guru dapat menggunakan alat-alat bantu seperti gambar, dan audio visual lainnya". Sedangkan (Sanjaya, 2010) menyatakan bahwa Metode Ceramah adalah " cara menyajikan pelajaran melalui penuturan secara lisan atau penjelasan langsung kepada sekelompok siswa”. Berdasarkan beberapa pendapat tersebut, dapat ditarik kesimpulan metode ceramah adalah sebuah interaksi antara guru dan siswa, siswa yang penulis artikan adalah kader Posyandu Asoka II Jatiranggon yang telah melaksanakan dan mengikuti pelaksanaan Pengabdian Kepada Masyarakat yang kami adakan melalui alat komunikasi secara lisan.

Pelatihan Keterampilan menggunakan microsoft Excel sebagai database nya yang bertujuan untuk mengurangi kesalahaan pendataan balita, pendaftaran baru, dan pencatatan agar lebih cepat atau up to date sesuai dengan kebutuhan kader Posyandu Asoka II Jatiranggon sehingga kebenaran isi database sangat berpengaruh pada kualitas laporan atau informasi yang dihasilkan. Latihan dimodifikasi sesuai situasi dan kondisi kemampuan peserta serta karakter materi pembelajaran, sehingga dapat meningkatkan keterampilan dalam menggunakan komputer dan microsoft Excel secara dasar dalam mengolah data-data posyandu Asoka II Jatiranggon.

Metode selanjutnya yang digunakan dalam penerapan IPTEK adalah kaji tindak partisipasif. Metode ini adalah kegiatan yang banyak melakukan pengambilan bagian, seperti mendengar, berbagi pengalaman, dan pembelajaran dari yang lain. ((curriculum for excellence building the curriculum 3 a framework for learning and teaching, 2008). Menurut (Sudjana, 2013) partisipatif berarti pengikutsertaan seseorang untuk melakukan sesuatu atau pengambilan bagian dari sesuatu yang harus dilakukan oleh pelakunya. Pembelajaran partisipasif dapat diartikan sebagai upaya pendidik untuk mengikutsertakan peserta didik dalam kegiatan pembelajaran. Pembelajaran partisipsif mengandung arti ikut sertanya peserta didik di dalam program pembelaajran partisipasif. Keikutsertaan peserta didik itu diwujudkan dalam tiga tahaapn kegiatan pembelajaran yaitu perencanaan program, pelaksanaan, dan penilaian kegiatan pembelajaran.

Untuk mencapai tujuan tersebut perlu penyadaran masyarakat khususnya kader yang berkenaan dengan permasalahan yang dihadapi, selanjutnya didorong untuk mencari alternatif pemecahan masalah yang lebih efektif melalui pendekatan kaji tindak (Igbal, dkk, 2007). Dalam prakteknya, tim PKM sebagai fasilitator dan pelaksana melakukan kegiatan PKM sesuai kesepakan dengan mitra yaitu Posyandu Asoka II Jatiranggon melalui tahapan yang direncanakan. Ini untuk memberikan petunjuk pelaksanaan PKM agar lebih terarah dan efektif. 


\section{HASIL DAN PEMBAHASAN}

Kegiatan Pengabdian Kepada Masyarakat dilakukan di Posyandu Asoka II Jatiranggon Bekasi. Mengingat semakin pentingnya penggunaan teknologi komputer khususnya dalam menunjang aktivitas Posyandu, hal ini sangat membutuhkan perhatian dan motivasi untuk peningkatan kualitas dan potensi diri para kader Posyandu Asoka II Jatiranggon Bekasi.

Pelaksanaan kegiatan pengabdian berlangsung pada hari Rabu tanggal 1 Mei 2019 dari jam 09.00 s.d Selesai, dengan dihadiri 10 kader Posyandu Asoka II Jatiranggon bekasi. Kegiatan pengabdian berlangsung dirumah kediaman Bapak RT. 01 yaitu Bapak. H. Kusnadi. Kegiatan pengabdian diawali dengan perkenalan dan identifikasi permasalahan dari pengolahan data Posyandu Asoka II Jatiranggon. Pelaksanaan kedua, pada tanggal 24 Mei 2019, berlangsung dengan kediaman yang sama pada pelaksanaan abdimas awal dengan melakukan pengenalan dan manfaat penggunaan komputer. Hasil yang didapat bahwa tidak seluruh kader Posyandu Asoka II Jatiranggon bisa mengoperasikan komputer secara umum. Namun tidak menghalangi para kader untuk tetap latihan dan berusaha untuk memahami mengoperasikan komputer.

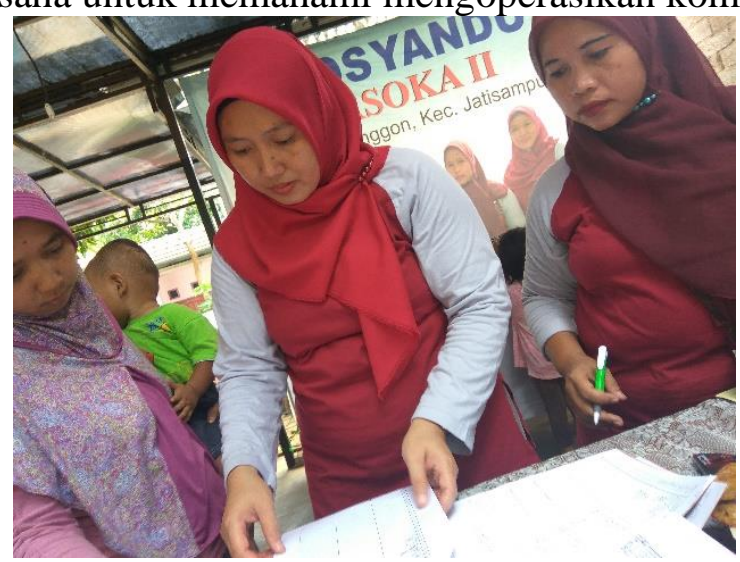

Gambar 2 Identifikasi Lapangan di Posyandu Asoka II Jatiranggon Bekasi Posyandu Asoka II Jatiranggon Bekasi

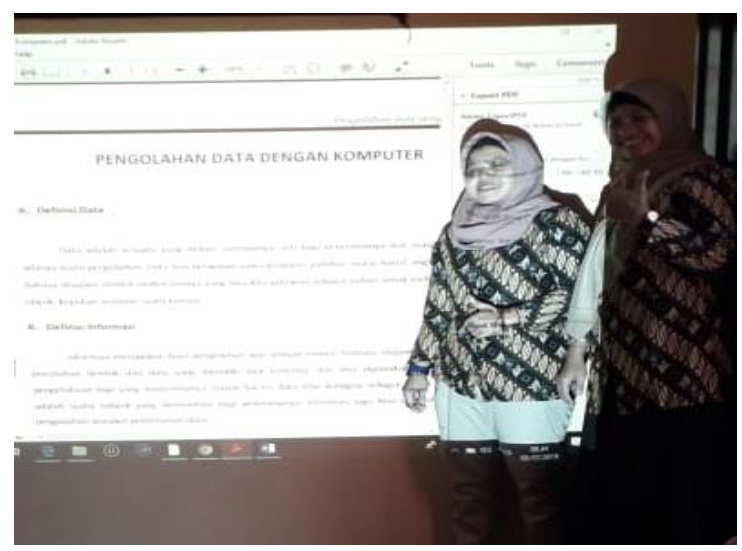

Gambar 3 Sosialisasi Pengenalan Komputer

Pelaksanaan kegiatan abdimas ketiga, pada tanggal 21 Juni 2019, dengan tempat yang sama, tim abdimas mulai melakukan pelatihan penggunaan Microsoft Excel untuk mengolah data secara efektif dan efesien. Membutuhkan waktu yang lama karena seperti dijelaskan pada kegiatan abdimas kedua, terjadinya kendala dari pengetahuan para kader 
dalam mengoperasikan komputer. Tim peneliti dalam mengatasi kendala tersebut, menyediakan modul dasar pelatihan Microsoft Excel yang digunakan adalah Micrososft office tahun 2008 atau ke atas sehingga memudahkan para kader dalam melakukan pengolahan data seperti membuat tabel data posyandu, data balita, dan lain sebagainya.

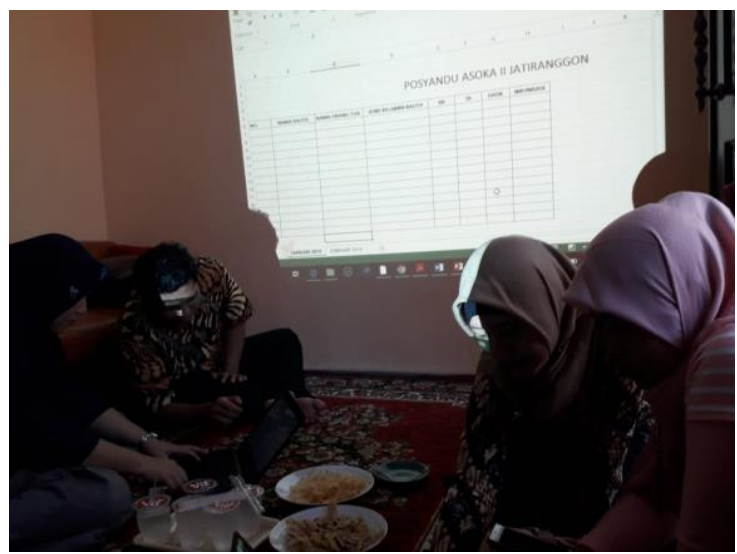

Gambar 4. Sosialisasi Pengolahan Data Dengan Microsoft Excel

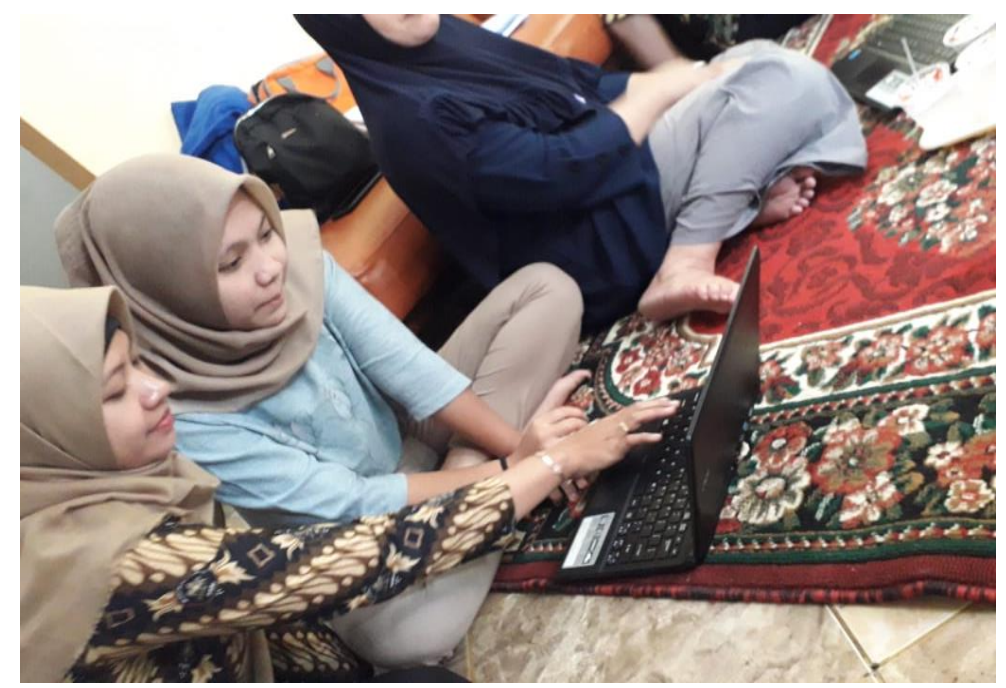

Gambar 5. Kegiatan PKM Kepada Posyandu Asoka II Jatiranggon Bersama Mahasiswa

Hasil yang dicapai berdasarkan wawancara, tanya jawab dan pengamatan langusng selama kegiatan berlangsung, kegiatan pengabdian pada masyarakat ini memberikan hasil sebagai berikut:

1. Meningkatnya pengetahuan dan pemahaman kader Posyandu Asoka II Jatiranggon dalam menggunakan komputer dan pengolahan data menggunakan Microsoft Excel.

2. Meningkatnya keterampilan kade Posyandu Asoka II Jatiranggon dalam menggunakan komputer dan juga menerapkan fungsi Microsoft Excel untuk kegiatan posyandu di bulan mendatang sehingga data-data yang diinput secara manual tidak lagi rusak dan mengurangi resiko kehilangan data posyandu.

Tim pengabdian masyarakat selama kegiatan menyediakan modul dan melakukan kegiatan publikasi yang sedang berjalan. 


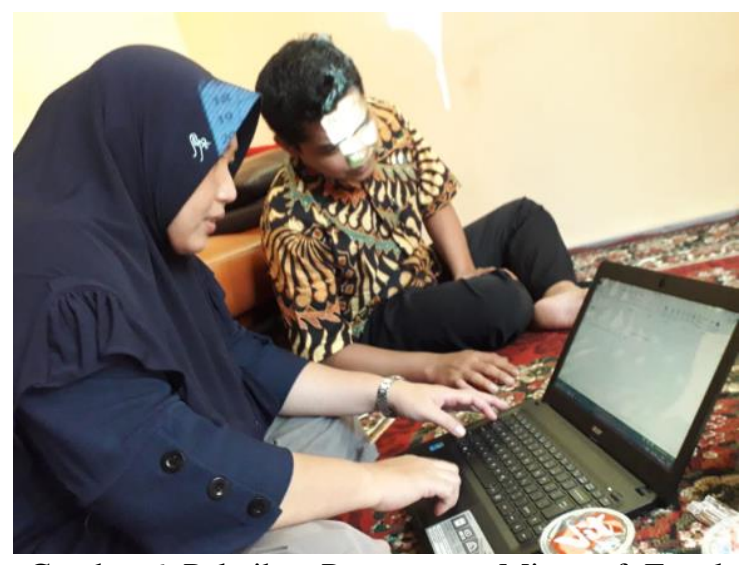

Gambar 6. Pelatihan Penggunaan Microsoft Excel

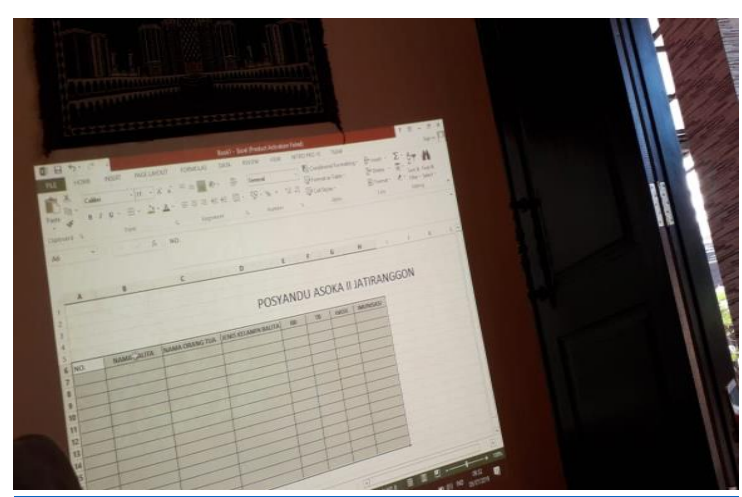

Gambar 7. Evaluasi Kegiatan Pengolahan Data

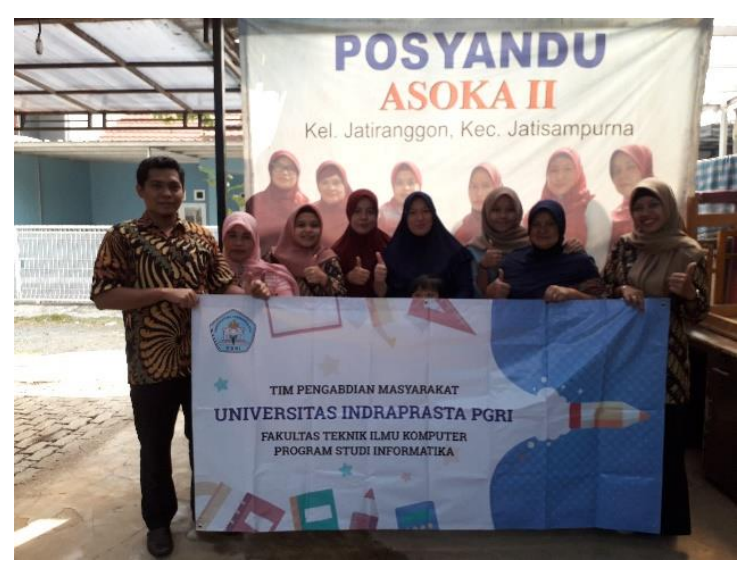

Gambar 8 Foto Bersama Kader Posyandu Asoka II Jatiranggon Bekasi

\section{SIMPULAN}

Dari kegiatan Pengabdian Kepada Masyarakat ini dapat disimpulkan bahwa:

1. Pengalaman baru dan keterampilan kader Posyandu Asoka II tentang pelatihan penggunaan komputer dan pengolahan data menggunakan Microsoft Excel dalam meningkatkan kemampuan pemahaman kader terhadap pengolahan data-data kegiatan posyandu, seperti daftar hadir posyandu, data balita, data imunisasi dan lain sebagainya. 
2. Pemahaman kader Posyandu Asoka II Jatiranggon tentang pentingnya penggunaan komputer dan pengolahan data menggunakan microsoft Excel dapat meningkatkan personal confidence terhadap pemeliharaan data.

Didapatkan 2 pertanyaan dari kader Posyandu terkait materi pelatihan tersebut mengharapkan ada kegiatan pelatihan kembali terkait pelatihan penggunaan komputer dan pengolahan data menggunakan Microsoft Excel.

\section{DAFTAR PUSTAKA}

curriculum for excellence building the curriculum 3 a framework for learning and teaching. (2008). the Scottish Government, June 2008.

Depkes-R.I., 2011. Pedoman Umum Pengelolaan Posyandu, Kementerian Kesehatan RI bekerjasama dengan Kelompok Kerja Operasional (POKJANAL POSYANDU). www.promles.depkes.go.id diakses 19 Januari 2019.

Efendi, Is. (2018). No TitlePENGARUH METODE CERAMAH TERHADAP MOTIVASI BELAJAR PAI SISWA KELAS XI MAN 5 JALAN MAGELANG KM. 17 MARGOREJO, TEMPEL, SLEMAN YOGYAKARTA. Yogyakarta. Retrieved from https://dspace.uii.ac.id/bitstream/handle/123456789/5547/Ismail Efendi $\% 2813422010 \% 29$.pdf? sequence $=1 \&$ isAllowed $=\mathrm{y}$

Iqbal, M., dan Sumaryanto. 2007. "Strategi Pengendalian Alih Fungsi Lahan Pertanian Bertumpu Pada Partisipasi Masyarakat". Pusat Analisis Sosial Ekonomi dan Kebijakan Pertanian. Volume 5 No. 2, Juni 2007: 167-182. Bogor.

Learning+Teaching Scotland. 2007. "Participative ang Learning." Scotland: Save the Childern.

Kemenkes R.I., 2012. Buku Pegangan Kader Posyandu: Ayo ke Posyandu Setiap Bulan, Kementerian Kesehatan Republik indonesia. Jakarta: Kementerian Republik Indonesia.

Prigianata, M. . (2013). No Title. J-INTECH, 1(1). Retrieved from http://garuda.ristekbrin.go.id/documents/detail/398528

Sanjaya, W. (2010). Strategi Pembelajaran Berorientasi Standar Proses Pendidikan, cet. VII, Jakarta: Prenada Media Group.

Sholiha, Nabila., kusumadewi, S. (2015). Sistem Informasi Posyandu Kesehatan Ibu dan Anak. In SISTEM INFORMASI POSYANDU KESEHATAN IBU DAN ANAK (pp. 207-214). Yogyakarta: Prosiding SNATIF ke -2 Tahun. Retrieved from https://jurnal.umk.ac.id/index.php/SNA/article/view/325

Sudjana, N. (2013). Dasar-dasar proses belajar. Jurnal Pendidikan. 